\title{
Pinus pinea: un reto para la agricultura de precisión
}

\section{Pinus pinea: a challenge for precision agriculture}

\section{Yeison Alejandro Aldana Rodríguez ${ }^{1}$}

○

Recepción: 30/09/2021
Aprobación: 07/12/2021

Publicación: 22/12/2021

Para citar este artículo

Aldana Rodríguez, Y. A. (2021). Pinus pinea: un reto para la agricultura de precisión. Indagare, (9), 88-95.

https://doi.org/10.35707/indagare/909 


\title{
Resumen
}

El conteo de piñas en cultivos de Pinus pinea se realiza de forma manual en una sección del árbol; esta información se puede usar para relacionarse con el rendimiento del cultivo. La agricultura de precisión facilita realizar esta labor de conteo al incluir vehículos aéreos no tripulados (VANT), acompañados de cámaras de alta resolución que permiten obtener imágenes que posteriormente son procesadas computacionalmente y en conjunto con técnicas clásicas y avanzadas de aprendizaje de máquina (o machine learning), que posibilitan una estimación del conteo más automatizada, precisa y rápida comparada con el conteo manual.

\begin{abstract}
Pine cone counting in Pinus pinea crops is done manually on a section of the tree; this information can be used to relate to crop yield. Precision agriculture facilitates this counting task by including unmanned aerial vehicles (UAVs), accompanied by high-resolution cameras that allow obtaining images that are subsequently processed computationally and in conjunction with classical and advanced machine learning techniques, which enable a more automated, accurate and faster estimation of the count compared to manual counting.
\end{abstract}

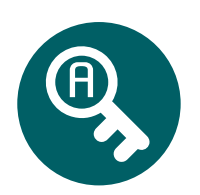

Palabras claves: Pinus pinea, agricultura de precisión, aprendizaje de máquina, aprendizaje profundo, procesamiento de imágenes, vehículos aéreos no tripulados (VANT).

Key words: Pinus pinea, precision agriculture, machine learning, deep learning, image processing, unmanned aerial vehicles (UAVs).

\section{Introducción}

Existen numerosas técnicas para automatizar total o parcialmente tareas agrícolas como siembra, recolección, procesamiento de productos, seguimiento de cultivos, entre otras. Es aquí donde la agricultura de precisión se ha convertido en un campo importante de investigación, aportando soluciones alternativas a problemas que se han resuelto por años de manera convencional. Una de las aplicaciones que está en auge los últimos años es la estimación de producción (Rahnemoonfar \& Sheppard, 2017), la cual toma relevancia en la gestión del manejo de recursos y personal de un proyecto agrícola. Puesto que lograr estimar la producción tiene demasiadas ventajas, no solo en temas de 
planificación operativa, sino también financiera, lo que es muy importante en cualquier tipo de cultivo para el agricultor. Este artículo hace referencia al caso del Pinus pinea y la investigación desarrollada en el Centro de Ciencia y Tecnología Forestal de Cataluña (CTFC) en conjunto con la Universidad de Ibagué, sobre la estimación de la producción a partir de imágenes captadas por VANT y posteriormente procesadas computacionalmente.

\section{Pinus pinea}

El Pinus pinea es un fruto muy popular en España y el mediterráneo europeo, es también conocido como pino piñonero, este tipo de pino es perteneciente a la familia de las pináceas, y su nombre es debido a que produce como frutos, grandes piñas. En una etapa inicial se cuenta con flores femeninas (Figura 1a), que al ser polinizadas se convierten en piñas (Figura 1b), las cuales, al madurar y abrir sus escamas, dejan caer sus semillas o piñones (Figura 1c y Figura 1d), las cuales son comestibles. España, primer productor mundial, recolecta las piñas entre los meses de noviembre y enero, cada tres años, tiempo promedio que tarda el pino en dar sus frutos (Figura 1e). Dado que esta semilla contiene $34 \%$ de proteína, un poco más que el maní y las almendras, con $26 \%$ y $15 \%$ respectivamente, además, posee ácidos insaturados cercanos al $93 \%$, vitaminas, entre otros beneficios. Tiene un valor comercial bastante elevado respecto a otras semillas similares como las almendras, que cuestan alrededor de 14 euros el kilogramo, mientras que los piñones oscilan entre los 60 y 70 euros cada kilogramo y son muy usadas en repostería, guarnición de ensaladas o platos en salsa.

Figura 1. a) Flor b) Piña c) piñón con cascara d) Piñón blanco e) Pinus pinea

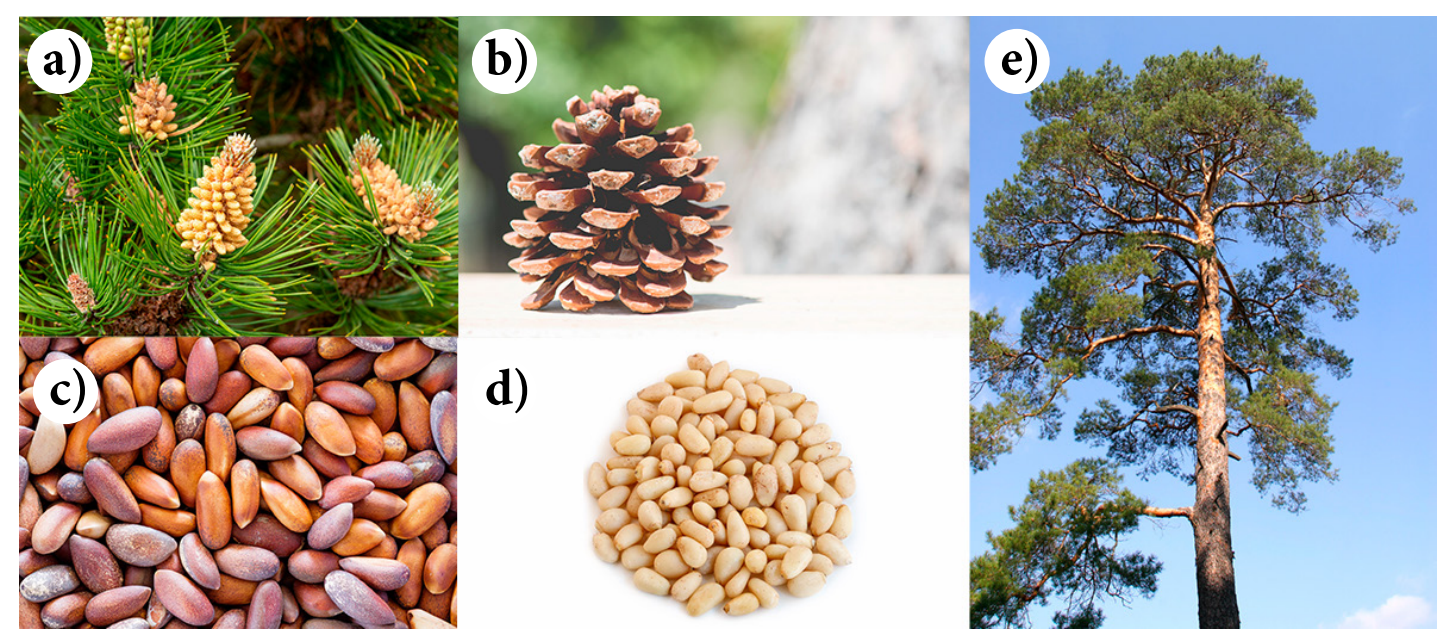

Fuente: Elaborado a partir de Franco Beleño, 2021 


\section{Problemática}

Un punto importante del Pinus pinea es su variabilidad en la producción, puesto que no existe certeza de un promedio de piñones en cada recolección, ya que este pino es muy susceptible a cambios en el clima. Es aquí donde se derivan algunos inconvenientes a la hora de la recolección, como desconocer el momento óptimo en el que se debe recoger la cosecha de un árbol en específico (por lo que se dificultaría escoger la cantidad de trabajadores a contratar para realizar la labor). También es ardua la labor de realizar una estimación árbol por árbol de la cantidad de semillas de la cosecha actual (lo que demandaría demasiado tiempo y la posibilidad de obtener resultados con alto índice de error).

A estas problemáticas se propuso como solución estimar la producción de este pino para tener un mayor control sobre todas las variables que pueden fluctuar en cada cosecha. Dadas las diferentes tareas que conlleva esta investigación, el equipo de trabajo que se conformó es bastante numeroso, puesto que no solo fue el trabajo de software y operación del VANT, sino que este proyecto viene desde la siembra de los pinos, su mantenimiento, hasta la estimación del conteo final, habiendo muchas personas involucradas, dentro de las que destacamos a: Shawn C. Kefauver, Jose L. Araus, Luisa Buchaillot y Joel Segarra de la Universidad de Barcelona; Xavier Llosa, del Consorcio Forestal de Cataluña (CFC); Mario Beltran, Centro de Ciencia y Tecnología Forestal de Cataluña (CTFC) y Míriam Piqué, del Joint Research Unit, CTFC.

\section{Selección de la cámara especializada}

Inicialmente se tomaron algunas muestras de piñones, semillas y madera, para analizarlas a través de un espectrofotómetro OceanOptics FLAME VIS-NIR, instrumento óptico para medir la intensidad de la luz en relación con la longitud de onda, lo que quiere decir que podemos obtener un gráfico que nos permite analizar qué tanta luz absorbe un material al iluminarlo. Esto fue un paso clave, pues mediante esta información es posible seleccionar qué cámara (sensor) se debía usar para realizar las diferentes tomas, obteniendo los mejores resultados y logrando diferenciar las partes del árbol (piñones, semillas y madera) de forma más clara. Con base en esta información se seleccionó la cámara RGB modificada GR-NIR de 12 MP, modificación que se hizo necesaria para capturar el verde, rojo e infrarrojo cercano. 


\section{Terreno de estudio y vanT}

Figura 2. a) creación de ortomosaicos a partir de imágenes tomadas por VANT

b) ejemplo de ortomosaico bosque nativo
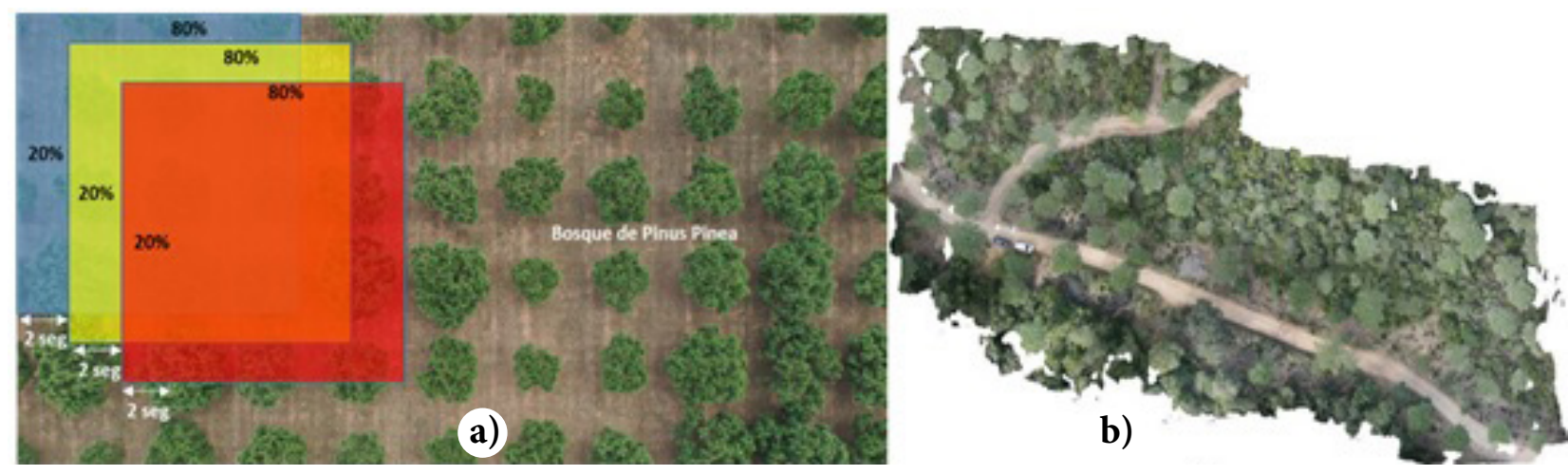

Fuente: Imágenes facilitadas por el CTFC

Esta investigación sobre esta técnica de estimación del conteo a través de procesamiento de imágenes se adelantó en Cataluña, España, cerca de los Pirineos franceses y, como se observa en la Figura 2a, el terreno de estudio es plano y los pinos se encuentran equidistantes uno del otro, dicho terreno se escogió así para facilitar la investigación; mientras que en la Figura $2 \mathrm{~b}$ vemos un ortomosaico de un bosque nativo. El vaNT escogido para realizar los sobrevuelos fue el DJI Mavic 322 Pro UAV al cual se le incorporó la cámara antes mencionada, con el objetivo de realizar tomas aéreas cada dos segundos y a partir de estas imágenes crear ortomosaicos, que son imágenes superpuestas, que al juntarlas crean un solo mapa del lugar, para este caso se usó un traslape del $80 \%$, como se muestra en la figura 2a, tomando más de 100 imágenes por cada ortomosaico. Además de las tomas aéreas realizadas por el VANT, también se hicieron tomas terrestres con la misma cámara, con el fin de obtener imágenes desde diferentes perspectivas, lo que en etapas posteriores del proyecto puede ser una herramienta muy útil para mejorar la capacidad de reconocimiento del sistema.

\section{Técnicas de machine learning}

El machine learning se está implementado en muchos productos que millones de personas usan diariamente, ejemplos como las plataformas de música YouTube, Spotify o películas como Netflix, que hacen un seguimiento a los intereses de los usuarios y con estos datos predicen los posibles gustos futuros. Hay un gran número de aplicaciones avanzadas del machine learning, como el reconocimiento de enfermedades a partir de 
imágenes o vehículos autónomos, entre otras (Shinde \& Shah, 2018). En pocas palabras, podemos decir que, partiendo de una muestra de datos, y posteriormente marcando ciertos parámetros de dicha muestra (entrenamiento), es posible que, al ingresar una nueva muestra de datos, se identifiquen de forma automática los parámetros marcados inicialmente debido a que el algoritmo logra aprender de este entrenamiento.

\section{Identificación y resultados}

Luego de tener los ortomosaicos listos junto con las imágenes terrestres, se usó una de las técnicas clásicas de machine learning llamada random forest, la cual permitió realizar pruebas de conteo de las piñas, como se muestra en la Figura 3, identificándolas posterior a un procesamiento de las imágenes originales y al entrenamiento del algoritmo. Al comparar los resultados respecto al conteo manual tradicional, se evidenció que en el conteo manual existía una variación respecto a la estimación esperada del $65 \%$, mientras que en el conteo automático basado en imágenes era del $25 \%$. Por lo que se redujo el error en un $40 \%$. A pesar de esto sigue habiendo algunos inconvenientes, como el alto follaje de los árboles cuando las piñas están maduras, esto hace que las hojas obstruyan la cámara cuando se toman las fotos desde el vaNT. A esta problemática se planteó el conteo ya no de las piñas en sí, sino de las flores en la etapa inicial, con el objetivo también de tratar de estimar la producción final.

Figura 3. Detección de piñas usando técnicas de machine learning
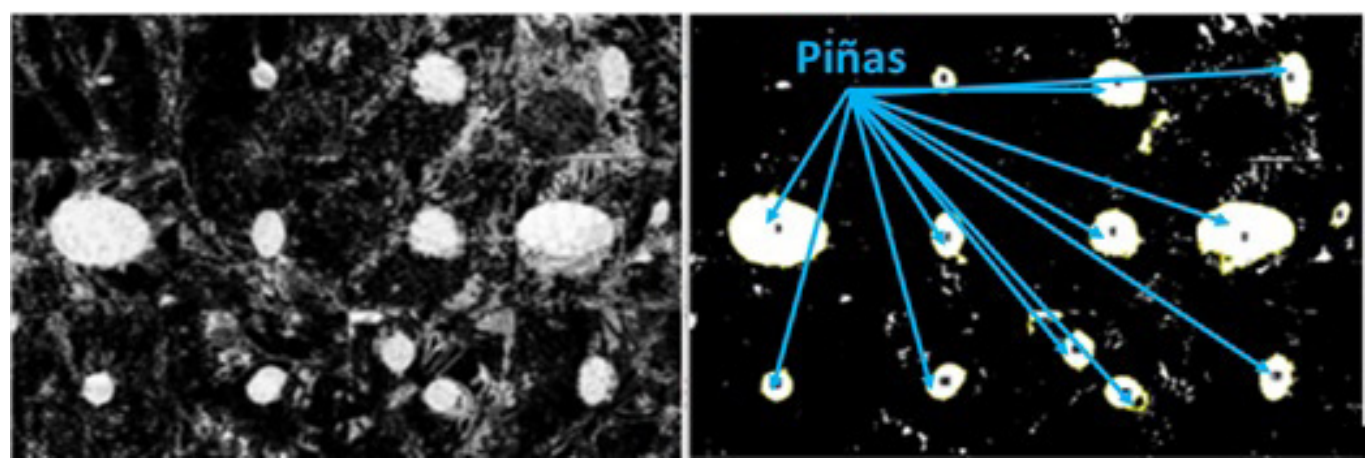

Fuente: Shawn et al., 2021 


\section{Variante del conteo de flores}

El estudiante del programa de Ingeniería Electrónica, Francisco Franco, bajo tutoría del docente PhD. José Armando Fernández de la Universidad de Ibagué, adelantan un trabajo de grado para realizar el conteo de las flores del Pinus italica. Esta investigación está en una etapa inicial y se espera aporte importantes resultados, pues presenta una forma alternativa para abordar el problema del conteo de las piñas, tratando de evitar el follaje espeso de la etapa cercana a la recolección, y permitiendo que el vANT capture mejores imágenes y el número de flores ocultas sea menor al número de piñas ocultas.

Figura 4. Imagen tomada por el vANT de árbol de Pinus italica y etiquetado de sus flores

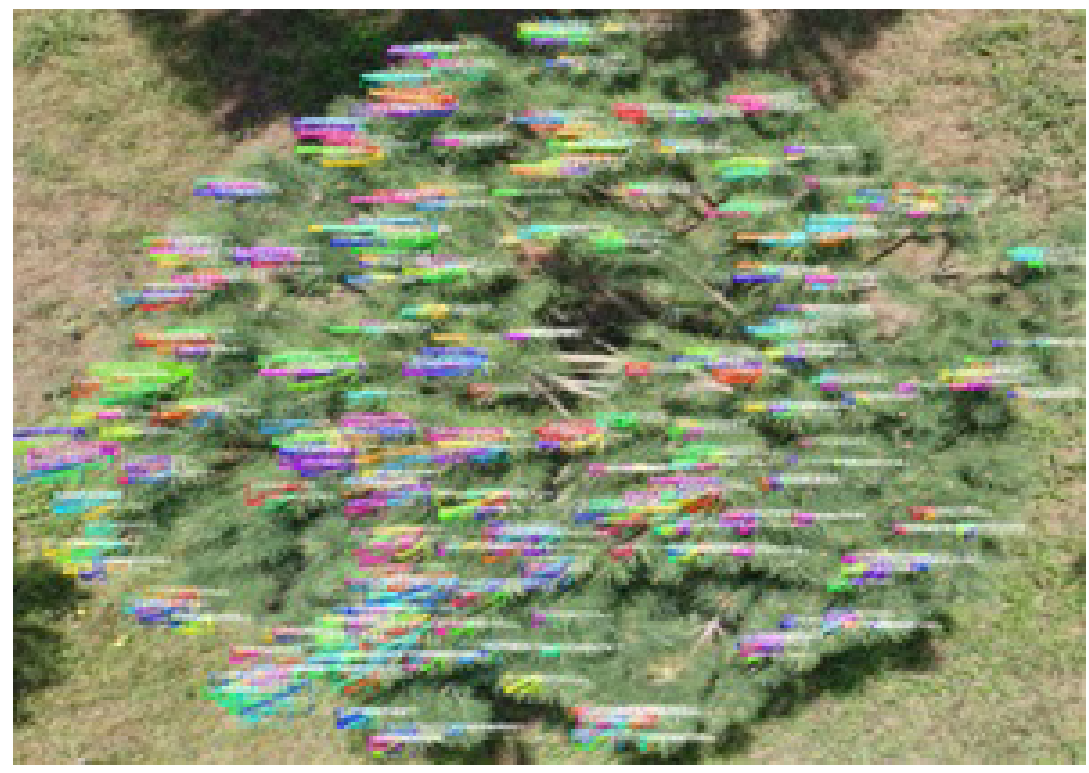

Fuente: Franco Beleño, 2021

También se está probando la variación en el ángulo en el que se toman las imágenes, ya que se ha notado que, al hacerlo, se logran ver flores que sin variar el ángulo no se podrían ver. En la Figura 4 se observa una imagen tomada por el vaNT y el etiquetado de las flores observadas para posterior procesamiento. Otra variante que se está implementando en esta investigación es el uso de técnicas de deep learning que, a diferencia del machine learning, deja la escogencia de los parámetros que caracterizarán a la imagen a la computadora, es decir, el deep learning puede aprender solo, y esto tiene ventajas, tales como pasar de usar cientos a millones de parámetros, permitiendo mejorar los resultados. 


\section{Conclusiones}

Esta investigación, la cual es pionera en el conteo de piñas del Pinus pinea y abre un mundo de posibilidades en este campo, ha mejorado los porcentajes de acierto respecto al método tradicional en un $40 \%$ aproximadamente, a pesar de esto surgen nuevas opciones que pueden mejorar los resultados iniciales en futuras investigaciones y que plantean alternativas como el conteo de flores en etapas tempranas, en lugar del conteo de la piña para luego estimar la producción, además del uso de técnicas de deep learning, por lo que se espera un futuro prometedor.

\section{Referencias}

Franco Beleño, F. J. (2021). Detección y conteo automático de flores de pino Pinus pinea utilizando una estrategia de deep learning en imágenes adquiridas desde plataforma aérea (Tesis de pregrado). Universidad de Ibagué, Ibagué, Colombia.

Rahnemoonfar, M., \& Sheppard, C. (2017). Deep Count: Fruit Counting Based on Deep Simulated Learning. Sensors, 17(4), 905. https://doi.org/10.3390/s17040905

Shawn C., K., Buchaillot, L., Segarra, J., Fernández Gallego, J. A., Araus, J. L., Llosa, X., Beltrán, M., \& Piqué, M. (2021). Quantification of Pinus pinea pinecone productivity using 2 machine learning of UAV and field images. Environmental Sciences Proceedings.

Shinde, P. P., \& Shah, S. (2018). A Review of Machine Learning and Deep Learning Applications. En Fourth International Conference on Computing Communication Control and Automation (ICCUBEA). https://doi.org/10.1109/ICCUBEA.2018.8697857 